\title{
THERE-AMALGAMS REVISITED: THE POSSIBILITY OF THERE BE AS A PARTICLE
}

\author{
ISAMU TAKAKI \\ Kyoto University
}

\begin{abstract}
Such there-sentences as There is a man wants to see you are called the There-Amalgam. While until now there have been two vying hypotheses to explain the construction, by far the dominant hypothesis has been that it consists of two clauses (i.e. [There is a man $]+[$ A man wants to see you $]$ ). The second hypothesis that there be in There-Amalgams is some kind of particle has hardly been accepted. In this paper, I present some stronger supporting evidence for this minor hypothesis than has ever before been seen with the help of the BNC, and argue that the particle-type as well as the amalgam-type does exist.*
\end{abstract}

Keywords: There-Amalgams, apo-koinou, particle, continuum, BNC

\section{Introduction}

One sub-type of There-Constructions in English such as (1) is called the There-Amalgam (henceforth, TA). ${ }^{1}$

* This article is a moderately revised excerpt (Chapter 4) from Takaki's 2009 unpublished master's thesis. That chapter, in turn, was a substantially revised and expanded version of Takaki (2008), presented at the 1st International Spring Forum of the ELSJ held at Tokyo University of Foreign Studies (April 2008). I first wish to express my deep gratitude to my mentor, Masa-aki Yamanashi, who gave me consistent guidance and illuminating comments throughout every stage of the present research. I also owe a huge debt of gratitude to Naoki Otani for instructing me in the fundamentals of a corpus-based approach to language. My equally deep thanks go to Daisuke Suzuki for his inspiration, advice and friendship, and to Michiko Yaguchi and two anonymous EL reviewers for their invaluable comments and suggestions. I am also indebted to Francesco Bolstad for improving my English. Finally, I am immensely grateful to Chiharu Kikuta for having encouraged me from my very first days in Cognitive Linguistics. Needless to say, all remaining errors are my own.

1 The term "amalgam" is by Lakoff (1974: 321), and by the term he means "a sentence which has within it chunks of lexical material that do not correspond to anything in the logical structure of the sentence."

English Linguistics 27: 1 (2010) 104-125 - 104-

(C) 2010 by the English Linguistic Society of Japan 
(1) a. There is a man at the door $\varphi$ wants to see you.

(Curme (1931: 236))

b. There's a lot of people $\varphi$ don't know that.

(Lambrecht (1988: 319))

c. There's they $\varphi$ got there.

$(\mathrm{BNC})^{2,3}$

As the name of the construction (i.e. "amalgam") indicates, the TA is considered to be composed of two parts by some scholars (e.g. [There is a man at the door $]+[$ A man at the door wants to see you $]$ ). Others postulate that there be in the TA is some kind of particle, and the construction consists of a single clause with a particle (e.g. [There is (= particle) $]+[A$ man at the door wants to see you]). There have been only a few scholars in favor of this latter hypothesis so far, and the former is generally regarded as more feasible.

Against this relatively firm preference for the "amalgam hypothesis," this paper aims to prove, by conducting a comprehensive corpus-based description of TAs, that the particle-type does exist. ${ }^{4}$ By building on the achievements of this, I argue that it is time to abandon the present prevailing idea of "amalgam-or-particle" and to positively seek the possibility of "amalgamand-particle."

In what follows, I will first overview some previous studies, and focus particularly on highlighting their failures. Section 3 introduces a methodology to resolve the problems identified in Section 2: A corpus-based approach. Section 4 investigates the comprehensive mass of authentic data of the TA from the BNC, uncovering some idiosyncrasies of the construction. In this section, the TA will be described from five morphological and syntactic perspectives: The subject-verb discord in number, the definite subject, the case of pronominal subjects, the "informationally rich" negative, and the contracted negative. Section 5 explores and discusses implications of the peculiarities of the TAs detected in Section 4. Section 6 offers concluding remarks.

2 The TA is not a firmly entrenched construction; it is only an ungrammatical and unacceptable construction for some native speakers of English.

3 Throughout this paper, the examples are from the BNC, unless otherwise indicated.

${ }^{4} \mathrm{I}$ do not mean to deny the amalgam-type. In this paper, I intend to balance the two hypotheses by presenting more supporting evidence for the former. 


\section{Previous Studies}

The syntactic arguments concerning TAs can be divided into two hypotheses, and in this paper they are referred to as the "Apo Koinou" Hypothesis and the "Particle" Hypothesis, respectively. ${ }^{5}$ As was already stated, the "Apo Koinou" Hypothesis is much more dominant than the "Particle" Hypothesis (Ando (2005), Curme (1931), Jespersen (1949), Lambrecht (1988), Prince (1981), Quirk et al. (1985)). It is true that there are some problems with this hypothesis, but basically I myself accept that this hypothesis also captures one aspect of TAs. Thus, I do not here discuss the problems of the "Apo Koinou" Hypothesis, and will instead, focus on highlighting some shortcomings of the "Particle" Hypothesis. ${ }^{6}$

\subsection{An Overview of the "Particle" Hypothesis}

There are only a few scholars who support the "Particle" Hypothesis (Harris and Vincent (1980), Yaguchi (2007, 2008), Yasui (1987)), and research on this hypothesis is inferior both in quantity and in quality to that on the "Apo Koinou" Hypothesis." Harris and Vincent (1980: 806) propose that the sentences in (2) should be analyzed as an independent clause with some kind of "existential particle."

(2) a. There's lots of people tried to help him.

b. There's two cars left already.

(Harris and Vincent (1980: 806))

Some pieces of supporting evidence are that There's in (2) is not marked for number, and that even tense marking is lost. Harris and Vincent do not discuss anything about the meaning of this particle, but Yasui (1987: 518-520) supports the concept of the "particle" construction, adding that the meaning of (3a) is equated with that of $(3 b)$ :

(3) a. There's a woman $\varphi$ wants to see you.

b. There's a woman who wants to see you.

(Yasui (1987: 518-519))

${ }^{5}$ In Tanaka et al. (1988: 37), an apo koinou is defined as "a construction in which a single phrase works on two elements at the same time, or has two distinct functions at the same time."

6 For the problems of the "Apo Koinou" Hypothesis, see Takaki (2009: Ch. 2).

7 In fact, Yaguchi does not use the term "particle" but "interjection" (an item for address). However, I classify her position into the "Particle" Hypothesis, since an interjection is a subcategory of particles (Ishibashi et al. (1973: 636), Tanaka et al. (1988: 468)). 
Yasui seems to assume that There's in (3a) is "attached" to a woman wants to see you. However, he makes no arguments on the reason for this "attachment," only stating that this is allowed because There's is only a device/ signal of existential sentences, that is, it does not change the semantics of $a$ woman wants to see you. ${ }^{8,9}$

\subsection{Problems}

I will here point out some problems with the "Particle" Hypothesis. First, although, in Harris and Vincent's research, the subject-verb disagreements in number and tense are given to verify the special status of There's as a particle, these types of phenomena can never be taken as supporting evidence: Such kinds of "bad" grammar can also be detected in every kind of linguistic expression. At least, in this case, the behavior of TAs should be compared with that of "normal" There-Constructions (henceforth, NTC).

Second, the data used for analysis is quite limited in number and variety. For example, there are only five examples of TAs analyzed in Harris and Vincent. In addition, although definite subjects are commonly found in TAs as we will see in Section 4, there are no examples in Harris and Vincent which include such kind of subjects. This strongly suggests that the data used for analysis is not well-composed, lowering the validity of their research.

Lastly, there is very likely to be one prevailing idea of "apo koinou-orparticle." 10 To my knowledge, not a single previous study seeks for or hints at the possibility of the coexistence of the two types of TA. In fact, there is no logical reason that we must stick to this idea, and we also need

8 Judging from the examples given in Harris and Vincent, their target seems to be there's, though they do not specify it. Yaguchi and Yasui, on the other hand, include the other environments (i.e. There is/are/-'re/was/were) within the scope of their research. In other words, what is regarded as a particle by Harris and Vincent is there's only, and by Yaguchi and Yasui, there be. As will be argued in Section 5, I take the latter position.

9 By the term "particle," Harris and Vincent seem to refer to an "uninflectable" item. "With/without inflections" is one of the traditional criteria for judging whether an item is a particle (e.g. Ishibashi et al. (1973: 636), Tanaka et al. (1988: 468)). By this criterion, there be, an inflectable item, cannot be recognized as a particle. However, the term is sometimes used more "loosely," as items which just have "peculiar semantics" and "idiosyncratic distributions," or ones which "do not fit easily into syntactic and semantic generalizations about the language" (Zwicky (1985: 290)). As will be stated again later, in my research I use the term "particle" in this broader sense.

10 Of course, this is not a problem only for the "Particle" Hypothesis: The scholars supporting the "Apo Koinou" Hypothesis also seem to be obsessed with this idea. 
to seek the possibility of "apo koinou-and-particle."

With these shortcomings in mind, in the next section I will introduce the methodology best suited for the present research.

\section{A Corpus-Based Approach to Language}

Here, I will introduce a corpus-based approach to language, from which this type of research can substantially benefit. This is because corpora offer examples and their contexts at the same time. Also, they help to exclude some individual biases in collecting examples. In this sense, a collection of self-constructed examples only blurs the realities. Moreover, the number of data in a corpus is large, and they have been collected from every kind of source, so that they are apparently a cross-section of all possible English variants. Thus, an English grammar based on corpora is not just a speculative grammar, but a definitive grammar with psychological reality (Hayase and Horita (2005: 186), Saito et al. (1998: 144)).

In closing, it can be seen that this kind of corpus-method for language analysis is compatible with the idea of a "Usage-Based Model" (Langacker (2002: Ch. 10)) which states that "structure, or regularity, comes out of discourse and is shaped by discourse in an ongoing process" (Hopper (1998: 156)). This idea is crucial especially in analyzing "bad" grammars. By effectively utilizing corpus data, we are able to obtain a large collection of relevant data regarding both spoken and written usage of the specific language characteristic of interest. Thus, using this comprehensive mass of data from corpora, we can ensure that our analysis will be both sufficient and valid. It is for these reasons that we will presently take a corpus-based approach to our study, accepting this as the most useful and persuasive method.

\section{A Corpus-Based Description}

As was stated earlier, there have been more elaborate and influential arguments in favor of the "Apo Koinou" Hypothesis than the "Particle" Hypothesis. Admittedly, intuition also suggests that the former is more feasible. In this section, in order to dispel this "illusion," the TA is described from "novel" angles, which eventually accomplishes two objectives: (i) To present some stronger supporting evidence than ever before for the, until now, less accepted "Particle" Hypothesis (or, to prove that the particle-type does exist); (ii) (Building on the achievements of (i)) To prove that the 
"Apo Koinou" and "Particle" Hypotheses, respectively, capture different aspects of TAs, that is to say, both types exist synchronically.

\subsection{Data Sampling}

Before going ahead and laying out our description of TAs, I will explain the procedures used for collecting examples of TAs for analyses. Throughout this research, I made use of the BNC for data-collecting, and the procedures used are outlined below:

(4) The procedures

a. Firstly, all the examples of There-Constructions (both TAs and NTCs), including such sequences as There is, There's, There are, There're, There was and There were were extracted from the BNC, by using the concordance software equipped for this function. ${ }^{11}$ Table 1 shows the number of occurrence of each sequence in each context (Each figure in the square brackets indicates the proportion of each sequence to the words in each context).

b. Secondly, 1,000 sentences were selected from the extracted sentences in each environment (from $(\mathrm{Sa})$ through $(\mathrm{Sf})$ and from (Wa) through (Wf) in Table 1), with the help of BNC's random sampling function.

c. Thirdly, "noises" such as (i) There's for There has, (ii) There is going to ..., and (iii) The authorities there are obsessed ... were removed. Table 2 shows the final number of There-Constructions used for analyses. ${ }^{12}$

d. Finally, all the examples of TAs were manually picked out from (Sa) through $(\mathrm{Sf})$ and from (Wa) through (Wf) in Table 2.

11 Like Nakazawa (2006) and Yaguchi (2007), this research also excludes such cases as auxiliaries (There must ... /There have been ... /There is going to ...) to simplify the arguments.

12 Because of $(4 \mathrm{c})$, the number of each sample is less than 1,000. Also, we have only 84 samples for There're in the spoken context, and 18, in the written context, because of their original shortage of actual tokens ( 87 and 20 , respectively). 
Table 1. The Frequency of There-Constructions in the BNC

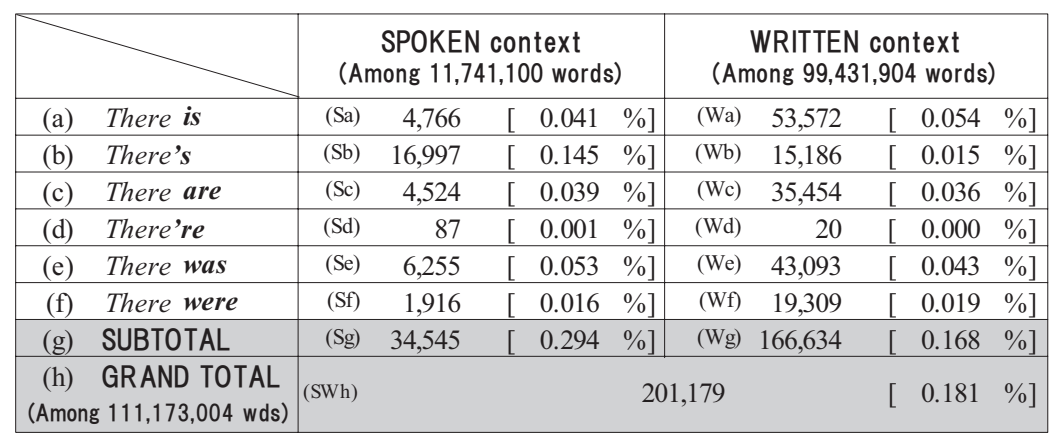

$(\%=\#$ of each sequence in each environment $\div \#$ of words in each environment $\times 100)$

Table 2. The Number of There-Constructions Selected for Analyses

\begin{tabular}{|c|c|c|c|c|c|c|c|}
\hline & \multicolumn{3}{|c|}{$\begin{array}{c}\text { SPOKEN context } \\
\text { (Among } 11,741,100 \text { words) }\end{array}$} & \multicolumn{4}{|c|}{$\begin{array}{c}\text { WRITTEN context } \\
\text { (Among } 99,431,904 \text { words) }\end{array}$} \\
\hline (a) There is & (Sa) & 973 & {$\left[\begin{array}{ll}0.008 & \%\end{array}\right]$} & (Wa) & 980 & [ 0.001 & $\%]$ \\
\hline (b) There's & $(\mathrm{Sb})$ & 951 & {$\left[\begin{array}{ll}0.008 & \%\end{array}\right]$} & $(\mathrm{Wb})$ & 944 & [ 0.001 & $\%]$ \\
\hline (c) There are & (Sc) & 983 & {$\left[\begin{array}{ll}0.008 & \%\end{array}\right]$} & $(\mathrm{Wc})$ & 990 & [ 0.001 & $\%]$ \\
\hline (d) There're & (Sd) & 84 & {$\left[\begin{array}{ll}0.001 & \%\end{array}\right]$} & (Wd) & 18 & {$[0.000$} & $\%]$ \\
\hline (e) There was & (Se) & 988 & {$\left[\begin{array}{ll}0.008 & \%\end{array}\right]$} & (We) & 971 & [ 0.001 & $\%]$ \\
\hline (f) There were & (Sf) & 979 & [ 0.008 \%] & $(\mathrm{Wf})$ & 987 & [ 0.001 & $\%]$ \\
\hline (g) SUBTOTAL & $(\mathrm{Sg})$ & 4,958 & {$\left[\begin{array}{ll}0.042 & \%\end{array}\right]$} & $(\mathrm{Wg})$ & 4,890 & [ 0.005 & $\%]$ \\
\hline $\begin{array}{l}\text { (h) GRAND TOTAL } \\
\text { (Among } 111,173,004 \text { wds) }\end{array}$ & (SWh) & & & & & [ 0.009 & \\
\hline
\end{tabular}

$(\%=\#$ of each sequence in each environment $\div \#$ of words in each environment $\times 100)$

Table 3 shows the numbers and the proportions of TAs with each sequence in each context. The sentences in (5) are some of the extracted examples of TAs:

Table 3. The Frequency of There-Amalgams in the BNC

\begin{tabular}{|c|c|c|c|c|c|c|c|c|c|}
\hline & & There is & & There's & There are & There're & There was & There were & TOTAL \\
\hline SPOKEN & & $\begin{array}{c}5 / 973 \\
0.5 \%\end{array}$ & (Sb) & $\begin{array}{c}27 / 951 \\
\mathbf{2 . 8} \%\end{array}$ & $\begin{array}{c}\text { (Sc) } 14 / 983 \\
1.4 \%\end{array}$ & $\begin{array}{c}\text { (Sd) } \quad \begin{array}{c}4 \\
\\
\end{array} \quad \mathbf{4 . 8} \%\end{array}$ & $\begin{array}{c}\text { (Se) } 22 / 988 \\
2.2 \%\end{array}$ & 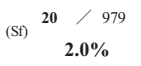 & $\begin{array}{c}\text { (Sg) } \\
92 / 4958 \\
1.9 \%\end{array}$ \\
\hline WRITTEN & (Wa) & $\begin{array}{c}\mathbf{1} / 980 \\
\mathbf{0 . 0} \% \\
\end{array}$ & $(\mathrm{~Wb})$ & $\begin{array}{c}5 / 944 \\
0.5 \% \\
\end{array}$ & $\begin{array}{cc}\text { (Wc) } & \mathbf{0} / 990 \\
& \mathbf{0 . 0} \% \\
\end{array}$ & $\begin{array}{cc}\text { (Wd) } & \mathbf{0} / 18 \\
& \mathbf{0 . 0 \%} \\
\end{array}$ & $\begin{array}{cc}\text { (We) } & \mathbf{3} / 971 \\
& \mathbf{0 . 3} \% \\
\end{array}$ & $\begin{array}{|cc|}\text { (Wf) } & \mathbf{0} / 987 \\
& \mathbf{0 . 0} \% \\
\end{array}$ & $\begin{array}{c}\text { (Wg) } \quad \mathbf{9} / 4890 \\
\\
\mathbf{0 . 2 \%}\end{array}$ \\
\hline TOTAL & & $\begin{array}{c}6 / 1953 \\
0.3 \%\end{array}$ & (Tb) & $\begin{array}{c}32<1895 \\
\mathbf{1 . 7} \%\end{array}$ & $\begin{array}{c}\text { (Tc) } 14 / 1973 \\
0.7 \%\end{array}$ & $\begin{array}{c}\text { (Td) } \quad \mathbf{4} / 102 \\
\quad \mathbf{3 . 9} \%\end{array}$ & 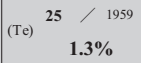 & (Tf) $\begin{array}{c}\mathbf{2 0} / 1966 \\
\mathbf{1 . 0} \%\end{array}$ & $\begin{array}{c}\text { (Tg) } 101 / 9848 \\
\mathbf{1 . 0} \%\end{array}$ \\
\hline
\end{tabular}

$(\%=\#$ of TAs in each environment $\div \#$ of constructions in each environment $\times 100)$ 
(5) a. There's they got there.

b. ... there're people in Congress want all kinds of different things and ...

c. ... there was, the girls have gone.

Throughout the following subsections, I will analyze these examples of TAs, focusing on their morphological and syntactic behaviors.

4.2. Morphological and Syntactic Behaviors of TAs and NTCs in the BNC 4.2.1. The Subject-Verb Discord in Number

In this subsection, attention is paid to the phenomenon of the subject-verb discord in number in TAs. It has been pointed out that, in There-Constructions, be-verbs and the following nouns often show discord in number as in (6) (Ando (2005: 686), Crawford (2005), Quirk et al. (1985: 1405)):
(6) a. ... there are a whole industry ...
(Crawford (2005: 42)) $)^{13}$
b. There's some people in the waiting room.

(Quirk et al. (1985: 1405))

It is true that such a phenomenon in There-Constructions is not rare, but the frequency of the $\mathrm{S}-\mathrm{V}$ discord in number in TAs must be spotlighted: The TA allows its logical subject to discord with the preceding be-verb much more frequently than the NTC does (Compare (Ag), 35.6\%, with (Ng), 4.3\%, in Table 4). Below are some examples of this phenomenon:

(7) a. ... there's more women drive now than ever they used to ...

b. ... there are basically a short term pension is available.

c. ... there was people went and quoted the number.

Table 4. The Frequency of the S-V Number Discord in Each Construction (TAs vs. NTCs)

\begin{tabular}{|c|c|c|c|c|c|c|c|c|c|}
\hline SPOKEN \& WRITTEN & & There is & There's & There are & & There're & There was & There were & TOTAL \\
\hline There-Amalgams & (Aa) & $\begin{array}{l}4 / 6 \\
66.7 \%\end{array}$ & (Ab) $\begin{array}{c}13 / 32 \\
40.6 \%\end{array}$ & $\begin{array}{ll}\text { (Ac) } & 3 / 14 \\
& 21.4 \%\end{array}$ & (Ad) & $\begin{array}{c}0 / 4 \\
0.0 \% \\
\end{array}$ & (Ae) $\begin{array}{c}10 / 25 \\
40.0 \%\end{array}$ & $\begin{array}{ll}\text { (Af) } & 6 / 20 \\
& 30.0 \% \\
\end{array}$ & (Ag) $\begin{array}{c}36 / 101 \\
35.6 \%\end{array}$ \\
\hline \begin{tabular}{|c|} 
“Normal" There- \\
Constructions \\
\end{tabular} & (Na) & $\begin{array}{c}16 / 1947 \\
\mathbf{0 . 8} \% \\
\end{array}$ & $\begin{array}{c}\text { (Nb) } \begin{array}{c}178 / 1863 \\
9.6 \%\end{array} \\
\end{array}$ & $\begin{array}{c}\text { (Nc) } \begin{array}{c}11 / 1959 \\
0.6 \%\end{array} \\
\end{array}$ & (Nd) & $\begin{array}{c}3 / 98 \\
3.1 \% \\
\end{array}$ & (Ne) $\begin{array}{c}137 / 1934 \\
7.1 \%\end{array}$ & $\begin{array}{cc} & 72 / 1946 \\
& \mathbf{3 . 7} \% \\
\end{array}$ & (Ng) $\begin{array}{c}417 / 9747 \\
4.3 \%\end{array}$ \\
\hline TOTAL & & $\begin{array}{c}20 / 1953 \\
\mathbf{1 . 0} \%\end{array}$ & $\begin{array}{c}\text { (Tb) } 191 / 1895 \\
\mathbf{1 0 . 1 \%}\end{array}$ & $\begin{array}{c}\text { (Tc) } 14 / 1973 \\
0.7 \%\end{array}$ & & $\begin{array}{c}3 / 102 \\
\mathbf{2 . 9} \%\end{array}$ & $\begin{array}{c}\text { (Te) } 147 \quad / 1959 \\
7.5 \%\end{array}$ & $\begin{array}{c}\text { (Tf) } \\
78 / 1966 \\
\mathbf{4 . 0 \%}\end{array}$ & $\begin{array}{c}(\mathrm{Tg}) \\
453 \quad / 9848 \\
4.6 \%\end{array}$ \\
\hline
\end{tabular}

$(\%=\#$ of the $\mathrm{S}-\mathrm{V}$ discord in each environment $\div$ \# of constructions in each environment $\times 100)$

This relatively high percentage of $\mathrm{S}-\mathrm{V}$ discord in TAs can no longer be ex-

13 Throughout this paper, the underlining in the example sentences is all mine. 
plained just by the general tendency of frequent S-V discord in There-Constructions. This is the first characteristic of TAs, which will be presented again later to support the "Particle" Hypothesis.

\subsubsection{The Definite Subject}

\subsubsection{The Definite Subject in General}

Let us move on to the next aspect: Definiteness of logical subjects in TAs. Preliminary to discussing TAs' logical subjects, I will take a brief look at the properties of logical subjects in There-Constructions in general.

It is said that a There-Construction is a new-information-introducing device, and therefore it typically allows an indefinite noun only in its subjectslot. However, in particular circumstances, a There-Construction accepts a definite noun as a logical subject. One important factor for a definite subject is "semantic newness/indefiniteness" (Ando (2008: 178), Kuno and Takami (2004: Ch. 10), Rando and Napoli (1978: 301)). For example, (8) is still acceptable in spite of its definite subject, since the noun (e.g. the leftover apple pie) is introduced as new information for the addressee.

(8) A: I'm hungry. Is there anything to eat?

B: Well, there's the leftover apple pie from last night.

(Kuno and Takami (2004: 152))

There is another particular type of there-sentence which accepts a definite subject: The List There-Sentence (henceforth, LTS). The acceptability of this type of there-sentence can also be explained by the notion of semantic indefiniteness. Rando and Napoli (1978: 300) maintain that (9) is accepted because the argument of the sentence is the list, not the individual members comprising the list. That is, even if each member in a list is old/given to an addressee, s/he does not know which/how many members are included in the list. This leads to semantic indefiniteness, hence the acceptance of LTSs.

(9) A: What's worth visiting here?

B: There's the park, a very nice restaurant, and the library.

Keeping these points in mind, let us now observe how a TA behaves with a definite subject. Table 5 exhibits the frequency of definite subjects in TAs and NTCs in the BNC, and below are the examples of TAs with definite subjects:

(10) a. ... there were, the place was specially big dustsheets ...

b. I'm just saying there was mine was Tech ...

$$
[\text { the }+\mathrm{N}]
$$

[possessive] 
c. There's Andrew look[s].

[proper noun]

d. ... there're you can do in a slightly different way ...

[personal pronoun]

Table 5. The Frequency of Definite Subjects in Each Construction (TAs vs. NTCs)

\begin{tabular}{|c|c|c|c|c|c|c|c|}
\hline SPOKEN \& WRITTEN & There is & There's & There are & There're & There was & There were & TOTAL \\
\hline There-Amalgams & $\begin{array}{ll}\text { (Aa) } & 3 / 6 \\
& \mathbf{5 0 . 0} \%\end{array}$ & $\begin{array}{c}\text { (Ab) } 11 / 32 \\
\\
\quad 34.4 \%\end{array}$ & $\begin{array}{ll}\text { (Ac) } & \mathbf{4} / 14 \\
& \mathbf{2 8 . 6} \%\end{array}$ & $\begin{array}{l}\mathbf{2} / 4 \\
\mathbf{5 0 . 0} \%\end{array}$ & $\begin{array}{ll}\text { (Ae) } & 9 / 25 \\
& \mathbf{3 6 . 0} \%\end{array}$ & $\begin{array}{l}3<20 \\
15.0 \%\end{array}$ & (Ag) $\begin{array}{c}32 / 101 \\
\\
\mathbf{3 1 . 7} \%\end{array}$ \\
\hline $\begin{array}{l}\text { "Normal” There- } \\
\text { Constructions }\end{array}$ & $\begin{array}{c}\text { (Na) } 104 / 1947 \\
5.3 \%\end{array}$ & $\begin{array}{c}\text { (Nb) } 168 / 1863 \\
9.0 \%\end{array}$ & $\begin{array}{cc} & \mathbf{3 6} / 1959 \\
\text { (Nc) } \quad \mathbf{1 . 8 \%}\end{array}$ & $\begin{array}{c}4 / 98 \\
4.1 \%\end{array}$ & $\begin{array}{c}\text { (Ne) } 147 / 1934 \\
7.6 \%\end{array}$ & $\begin{array}{cc}\text { (Nf) } & \mathbf{5 1} / 1946 \\
& \mathbf{2 . 6 \%}\end{array}$ & $\begin{array}{c}\text { (Ng) } 510 \quad / 9747 \\
5.2 \%\end{array}$ \\
\hline TOTAL & $\begin{array}{c}\text { (Ta) } 107 / 1953 \\
5.5 \%\end{array}$ & 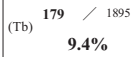 & $\begin{array}{cc}\text { (Tc) } & \mathbf{4 0} / 1973 \\
& \mathbf{2 . 0} \%\end{array}$ & $\begin{array}{c}6{ }^{6} / 102 \\
5.9 \%\end{array}$ & 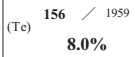 & 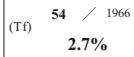 & 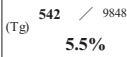 \\
\hline
\end{tabular}

$(\%=\#$ of definite subjects in each environment $\div \#$ of constructions in each environment $\times 100)$

As can be seen in Table 5, a definite noun as a logical subject occurs far more frequently in TAs (31.7\%) than in NTCs (5.2\%). Here, obviously there are no LTSs in (10), and then this phenomenon must be accounted for by the broader notion of semantic indefiniteness. ${ }^{14}$ Let us examine (10a) first, repeated as (11) with its context from the BNC.

(11) And every big mansion house had a place about at_least ten feet away_from the house, where they had a store for holding the tins. And each of the places er where we got the supply of tins, er we had a little van that went out to deliver the tins and we delighted as boys, going out, carrying the two tins er into the place. And er the cars then of_course were all painted in, there were no cellulose paint, we had a paint shop there but er it, and we had an old painter who used to paint the cars in enamel and they were an awful lot of work on them. And of_course you had to have great dustsheets to keep the dust. Because if it had been painted, and the paint took quite a long time to dry and er if there was a speck of dust it remained there forever. Or you would have to take the whole thing off again. So there were, the place was specially big dustsheets and kept the dust off the paint.

The speaker of (11) is talking about painting, and the phrase in question is

14 In fact, among the 101 examples of TAs there is only one LTS:

(i) There is also Laura, 17, me, 15, and William is 12 . 
the place in the last sentence. Clearly, what the place refers to appears in the earlier parts of the passage. Thus, the place is both morphologically and semantically old, and in this situation, specially big dustsheets would be "new" information. That is, it is postulated here that a grammatical and more "logically and semantically accurate" counterpart sentence to the TA in (11) may be there were specially big dustsheets $\mathrm{s}_{\mathrm{i}}$ at the place which $\mathrm{i}_{\mathrm{i}}$ kept the dust off the paint.

Next, let us examine (10d), repeated as (12) below with its context.

(12) ... what I usually do when I do an exam is I spend the first five minutes actually looking at the questions because initially you look for the ones that you've revised and you see but there may be others there, there're you can do in a slightly different way than the way that they first appear and that might help you quite a bit, although there are no trick questions in this.

The speaker of (12) is telling the addressee(s) about some tactics for exams. In this situation, you is not only morphologically but also semantically old/given. Actually, a slightly different way in (12) is both morphologically and semantically new. That is, a more "accurate" way to express the underlined part in the above sentence may be there's a slightly different way in which you can do it. ${ }^{15}$

In the same vein, (some) logical subjects in our 32 examples of definite subjects are also unlikely to be semantically new. ${ }^{16}$ It is not surprising that a definite noun is incompatible with the notion of newness. Therefore, even without considering any other factors, Table 5 alone signals that TAs are going in an unexpected direction. This second idiosyncrasy more strongly verifies the "Particle" Hypothesis, as will be discussed in more detail in Section 5.

\subsubsection{The Personal Pronoun}

Here, among the definite subjects, I focus particularly on personal pronominal subjects which are distinctly worthy of more careful study. Table 6 shows the frequency of pronominal subjects in TAs and NTCs in the

15 In fact, it is not easy to interpret TAs like in (11) and (12) because of their strange and unexpected behaviors, and some argue against my interpretations. However, here we shall have no further discussions on this point, as it has no direct connection with the main subject.

16 Actually, I have judged Andrew in (10c) semantically new, from the context in the BNC. 
BNC, and below are some examples of TAs with pronominal subjects: ${ }^{17}$

(13) a. But there is We $[s i c]$ can come to that in a moment if we may.

b. ..., there're you can do in a slightly different way ... (=(10d))

c. ... there were it was big caverns that'd be underground.

Table 6. The Frequency of Personal Pronominal Subjects in Each Construction (TAs vs. NTCs)

\begin{tabular}{|c|c|c|c|c|c|c|c|c|c|c|c|c|c|c|}
\hline SPOKEN \& WRITTEN & & There is & & There's & & here are & & There're & & here was & Th & ere were & & TOTAL \\
\hline There-Amalgams & (Aa) & $\begin{array}{l}2 / 6 \\
33.3 \%\end{array}$ & $(\mathrm{Ab})$ & $\begin{array}{l}9 / 32 \\
\mathbf{2 8 . 1} \%\end{array}$ & (Ac) & $\begin{array}{l}3 / 14 \\
\mathbf{2 1 . 4} \%\end{array}$ & (Ad) & $\begin{array}{l}2 \quad / 4 \\
\mathbf{5 0 . 0} \%\end{array}$ & $(\mathrm{Ae})$ & $\begin{array}{l}\mathbf{5} / 25 \\
\mathbf{2 0 . 0} \%\end{array}$ & (Af) & $\begin{array}{l}2 / 20 \\
10.0 \%\end{array}$ & (Ag) & $\begin{array}{l}23 / 101 \\
\mathbf{2 2 . 8} \%\end{array}$ \\
\hline $\begin{array}{l}\text { “Normal” There- } \\
\text { Constructions }\end{array}$ & & $\begin{array}{c}\mathbf{1} / 1947 \\
\mathbf{0 . 1 \%}\end{array}$ & $(\mathrm{Nb})$ & $\begin{array}{l}\mathbf{5} / 1863 \\
\mathbf{0 . 3} \%\end{array}$ & $(\mathrm{Nc})$ & $\begin{array}{l}\mathbf{1} / 1959 \\
\mathbf{0 . 1} \%\end{array}$ & $(\mathrm{Nd})$ & $\begin{array}{c}1 / 98 \\
\mathbf{1 . 0} \%\end{array}$ & $(\mathrm{Ne})$ & $\begin{array}{l}7 / 1934 \\
\mathbf{0 . 4 \%}\end{array}$ & $(\mathrm{Nf})$ & $\begin{array}{l}\mathbf{2} / 1946 \\
\mathbf{0 . 1} \%\end{array}$ & $(\mathrm{Ng})$ & $\begin{array}{c}17 / 9747 \\
0.2 \%\end{array}$ \\
\hline TOTAL & & $\begin{array}{l}3 / 1953 \\
0.2 \%\end{array}$ & (Tb) & $\begin{array}{c}14 / 1895 \\
0.7 \%\end{array}$ & (Tc) & $\begin{array}{l}4 / 1973 \\
0.2 \%\end{array}$ & (Td) & $\begin{array}{l}3 / 102 \\
2.9 \%\end{array}$ & $(\mathrm{Te})$ & $\begin{array}{c}12 / 1959 \\
\mathbf{0 . 6 \%}\end{array}$ & $(\mathrm{Tf})$ & $\begin{array}{l}\mathbf{4} / 1966 \\
\mathbf{0 . 2} \%\end{array}$ & $(\mathrm{Tg})$ & $\begin{array}{c}\mathbf{4 0} / 9848 \\
0.4 \%\end{array}$ \\
\hline
\end{tabular}

$(\%=\#$ of personal pronominal subjects in each environment $\div$ \# of constructions in each environment $\times 100$ )

Because we have already seen that, generally, definite subjects occur more often in TAs than in NTCs, the results in Table 6, in a sense, are not surprising. However, with these results we can safely add that personal pronouns have much more distinctive distributions (22.8\% vs. $0.2 \%$ ) (cf. $31.7 \%$ vs. $5.2 \%$ in Table 5).

More importantly, the reason why I address personal pronouns here is that they have declensions. The remainder of this subsection is devoted to the analysis of the case of pronominal subjects in There-Constructions. Before tackling the main subject, let us observe some of the rules for identifying relevant cases. First, look at the sentences below.

(14) a. Yes, it is $\{$ she/her $\}$.

b. It is $\{\mathrm{I} / \mathrm{me}\}$ she loves.

c. This is $\{$ he/him $\}$.

(Ando (2005: 691))

Above are the examples of the subject-complement concord in case. Prescriptive grammar says that a subject complement has to agree in case with the subject of the sentence (i.e. the nominative), because logically the subject complement represents the same entity as the subject does (cf. Ishibashi et al. (1973: 887)). Nevertheless, there is at least one other option, known in daily usage as the accusative. Ando (2005: 691) notes on this matter

17 The examples of a personal pronoun subject in Table 6 do not include such cases as (i) ... there are a lot of us who'd like to be able to do it and (ii) There were more of them than there used to be. Here, only "pure" personal pronouns as in (13) are counted. 
that the nominative for a subject complement is quite a formal style, and in a less formal style the accusative substitutes for the nominative (cf. Huddleston and Pullum (2002: 507), Ishibashi et al. (1973: 887), Watanuki et al. (2000: 175)). The motivation for the use of the accusative instead of the nominative may be that the speaker/writer feels the position to the left of a be-verb to be "subject territory," and the position to the right to be "object territory" (Ando (2005: 692)).

In addition to the reason just mentioned above, Ando (2005: 691-692) suggests that there exists another motivation for the use of the first personal pronoun in the accusative (i.e. $m e$ ) as in (14b), and (15).

(15) a. It is I who am at fault.

b. It is me who is at fault.

(Huddleston and Pullum (2002: 507))

c. The only one who objected was $\{? \mathrm{I} / \mathrm{me}\}$.

d. [Looking at a photo]

This one here is $\left\{{ }^{*} \mathrm{I} / \mathrm{me}\right\}$ at the age of 12 .

(Ando (2005: 691))

According to Ando (2005: 692), using me instead of $I$ is related to "objectification" of one(my)self, which accounts for the reason why the second $b e$-verb in (15b) is is. Moreover, in a situation like (15d) where one sees her/himself in the past from the present time, s/he is very likely to objectify her/himself.

To sum up, there may be several motivations for the use of the accusative instead of the nominative for a subject complement, and the former seems to be used more frequently in actual situations, regardless of the rules set down by prescriptive grammar.

Having confirmed this behavioral characteristic of pronouns, let us now return to the main topic of the case of a personal pronominal subject in TAs. From the 101 examples of TAs, I manually picked up all the sentences with a personal pronominal subject, and counted the number of pronouns in the nominative case. The results are shown in Tables 7 and 8 with some examples of TAs containing nominative pronoun subjects below:

(16) a. But there is We $[\mathrm{sic}]$ can come to that in a moment if we may. $\quad(=(13 a))$

b. ... there's I wish you'd shut up about you and your royalty!

c. There's they got there. $(=(1 \mathrm{c}))$

d. ... there are he is appearing for many others.

The results verify the hypothesis that, with regard to NTCs, in cases where there is an option between the nominative and the accusative, the latter is 
Table 7. The Frequency of Nominative Pronoun Subjects in Each Construction (TAs vs. NTCs)

\begin{tabular}{|c|c|c|c|c|c|c|c|c|c|c|c|c|c|c|}
\hline SPOKEN \& WRITTEN & & There is & & There's & & here are & & here're & & here was & & ere were & & TOTAL \\
\hline There-Amalgams & (Aa & $\begin{array}{l}2 / 6 \\
33.3 \%\end{array}$ & $(\mathrm{Ab}$ & $\begin{array}{l}5 / 32 \\
15.6 \%\end{array}$ & (Ac) & $\begin{array}{c}1<14 \\
7.1 \%\end{array}$ & (Ad) & $\begin{array}{c}0<4 \\
0.0 \%\end{array}$ & (Ac) & $\begin{array}{l}\mathbf{5} / 25 \\
\mathbf{2 0 . 0} \%\end{array}$ & (Af) & $\begin{array}{c}\mathbf{1} / 20 \\
\mathbf{5 . 0} \%\end{array}$ & (Ag) & $\begin{array}{c}14<101 \\
\mathbf{1 3 . 9} \%\end{array}$ \\
\hline $\begin{array}{c}\text { “Normal” There- } \\
\text { Constructions }\end{array}$ & & $\begin{array}{l}\mathbf{0} \succ^{1} 1947 \\
\mathbf{0 . 0} \%\end{array}$ & $(\mathrm{Nb}$ & $\begin{array}{l}\mathbf{0} / 1863 \\
\mathbf{0 . 0} \%\end{array}$ & $(\mathrm{Nc})$ & $\begin{array}{l}\mathbf{0} / 1959 \\
\mathbf{0 . 0} \% \\
\end{array}$ & (Nd) & $\begin{array}{c}\mathbf{0} / 98 \\
\mathbf{0 . 0} \%\end{array}$ & $(\mathrm{Ne})$ & $\begin{array}{l}\mathbf{2} / 1934 \\
\mathbf{0 . 1} \%\end{array}$ & $(\mathrm{Nf})$ & $\begin{array}{l}\mathbf{0} / 1946 \\
\mathbf{0 . 0} \%\end{array}$ & $(\mathrm{Ng})$ & $\begin{array}{c}\mathbf{2} / 9747 \\
\mathbf{0 . 0} \%\end{array}$ \\
\hline TOTAL & & $\begin{array}{c}\mathbf{2} / 1953 \\
\mathbf{0 . 1} \%\end{array}$ & (Tb) & $\begin{array}{c}\mathbf{5} / 1895 \\
\mathbf{0 . 3} \%\end{array}$ & (Tc) & $\begin{array}{l}\mathbf{1} / 1973 \\
\mathbf{0 . 1} \%\end{array}$ & (Td) & $\begin{array}{c}\mathbf{0} / 102 \\
\mathbf{0 . 0} \%\end{array}$ & (Te) & $\begin{array}{l}7 / 1959 \\
\mathbf{0 . 4} \%\end{array}$ & (Tf) & $\begin{array}{l}\mathbf{1} / 1966 \\
\mathbf{0 . 1} \%\end{array}$ & $(\mathrm{Tg})$ & $\begin{array}{c}16 / 9848 \\
0.2 \%\end{array}$ \\
\hline
\end{tabular}

$(\%=\#$ of nominative pronoun subjects in each environment $\div \#$ of constructions in each environment $\times 100$ )

Table 8. Breakdown of the Personal Pronominal Subjects

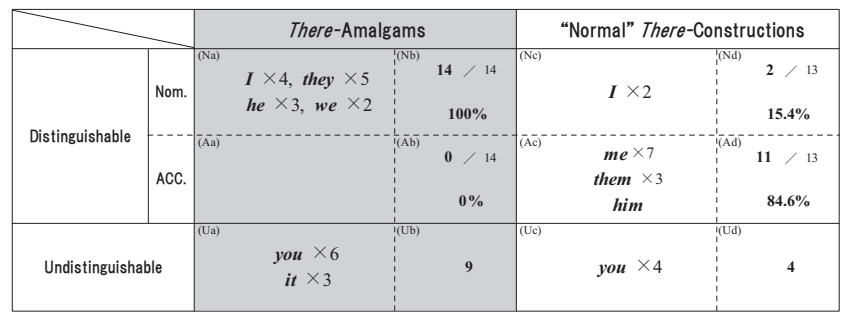

$(\%=\#$ of personal pronominal subjects in each case $\div$ \# of "distinguishable" personal pronominal subjects in each construction $\times 100$ )

often chosen (See $(\mathrm{Ng})$ in Tables 7, and (Ad) in Table 8). On the other hand, personal pronouns in the accusative never occur in TAs, instead, the frequency of the nominative increases (See $(\mathrm{Ag})$ in Tables 7 , and $(\mathrm{Nb})$ in Table 8). In other words, pronouns in TAs behave in a way contrary to the "normal" "everyday" usage.

Here, some may not think that this phenomenon is peculiar to TAs, and would probably argue that this can be explained just by the notion of "attraction" as (17) can. ${ }^{18}$

(17) a. No one but he showed much interest in the proposal.

b. ... let's you and I start at the very beginning of this thing.

(Ishibashi et al. (1973: 105))

In (17a), he is "attracted" to what it is (not him) by the following verb, showed. Likewise, in (17b), I is "attracted" by start. The environ-

18 Attraction is a process in which a grammatical or logical discord is provoked by a word or a phrase in a sentence, and it reflects speakers' tolerant attitudes toward anacolutha (Ishibashi et al. (1973: 105)). 
ments where attraction is caused, and the phenomenon itself are very similar to those of TAs, so that this notion may have to some degree to do with TAs. However, this concept alone is unlikely to be able to explain such a high frequency of the nominative pronoun subjects $((\mathrm{Nb})$ in Table 8). Some more feasible account will be proposed in Section 5.

Be that as it may, Section 4.2.2 has described the two peculiarities of TAs, which give relatively strong support to the "Particle" Hypothesis.

\subsubsection{The Negative}

Lastly, in this subsection, we will explore the behavior of the ThereConstruction in negative sentences. Here, by the "negative," I mean such constructs as negate a predicate (e.g. not, never, hardly, no longer, seldom, etc.). ${ }^{19}$ Table 9 exhibits the frequency of negatives in TAs and NTCs, and some examples of TAs with negatives are given below:

(18) a. ... but there's not you got some.

b. There are not three thousand four hundred signatures say this thing should be refused.

c. There aren't many people say that nowadays.

Table 9. The Frequency of Negatives in Each Construction (TAs vs. NTCs)

\begin{tabular}{|c|c|c|c|c|c|c|c|c|c|c|c|c|}
\hline SPOKEN \& WRITTEN & & There is & & There's & & here are & & here're & & here was & There were & TOTAL \\
\hline There-Amalgams & (Aa) & $\begin{array}{c}0 / 6 \\
0.0 \% \\
\end{array}$ & (Ab) & $\begin{array}{l}4 / 32 \\
12.5 \% \\
\end{array}$ & (Ac) & $\begin{array}{l}3 / 14 \\
\mathbf{2 1 . 4} \%\end{array}$ & (Ad) & $\begin{array}{c}0 / 4 \\
0.0 \% \\
\end{array}$ & (A & $\begin{array}{c}0 / 25 \\
0.0 \% \\
\end{array}$ & $\begin{array}{cc}\text { (Af) } & \mathbf{0} / 20 \\
& \mathbf{0 . 0} \%\end{array}$ & $\begin{array}{l}\text { (Ag) } \quad 6 / 101 \\
\quad 6.9 \% \\
\end{array}$ \\
\hline $\begin{array}{l}\text { “Normal" There- } \\
\text { Constructions }\end{array}$ & (Na) & $\begin{array}{c}120 / 1947 \\
6.2 \% \\
\end{array}$ & $(\mathrm{Nb})$ & $\begin{array}{c}46 / 1863 \\
\mathbf{2 . 5} \%\end{array}$ & (Nc) & $\begin{array}{c}\mathbf{5 2} / 1959 \\
\mathbf{2 . 7 \%}\end{array}$ & (Nd) & $\begin{array}{c}3 / 98 \\
\mathbf{3 . 1} \%\end{array}$ & (Ne) ${ }^{8}$ & $\begin{array}{c}\mathbf{8 7} / 1934 \\
\mathbf{4 . 5} \%\end{array}$ & $\begin{array}{c}\text { (Nf) } \\
\mathbf{7 5} / 1946 \\
\mathbf{3 . 9} \% \\
\end{array}$ & $\begin{array}{c}\text { (Ng) } 383 \quad / 9747 \\
3.9 \%\end{array}$ \\
\hline TOTAL & & $\begin{array}{c}120 / 1953 \\
6.1 \%\end{array}$ & (Tb) & $\begin{array}{c}50 / 1895 \\
2.6 \%\end{array}$ & (Tc) & $\begin{array}{c}55 / 1973 \\
2.8 \%\end{array}$ & (Td) & $\begin{array}{l}3 / 102 \\
2.9 \%\end{array}$ & (Te) ${ }^{8}$ & $\begin{array}{c}87>1959 \\
4.4 \%\end{array}$ & $\begin{array}{c}\text { (Tf) } \\
\mathbf{7 5} / 1966 \\
\mathbf{3 . 8 \%}\end{array}$ & 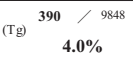 \\
\hline
\end{tabular}

$(\%=\#$ of negatives in each environment $\div \#$ of constructions in each environment $\times 100)$

Table 9 tells us that there is no significant difference in the distribution of negative to positive sentences between TAs and NTCs. However, deeper analyses of the results lead to the discovery of two notable behaviors of negative constructions. Take care to observe the tables below. Table 10 exhibits the frequency of "informationally rich" negatives (the negatives in gray in Tables 11 and 12) in each construction, and Tables 11 and 12 each

19 As will be argued in Section 5, my aim here is to show that, in some TAs, a beverb more or less has lost its "verbness." This aim can be achieved by investigating the negatives mentioned above, not by investigating such ones as negate a noun (e.g. no, few, little, etc.). 
Table 10. The Frequency of "Informationally Rich" Negatives in Each Construction (TAs vs. NTCs)

\begin{tabular}{|c|c|c|c|c|c|c|c|c|c|c|c|c|c|c|}
\hline SPOKEN \& WRITTEN & & There is & & There's & & here are & & here're & & here was & The & ere were & & TOTAL \\
\hline There-Amalgams & (Aa & $\begin{array}{c}0 / 6 \\
0.0 \%\end{array}$ & $(\mathrm{Ab})$ & $\begin{array}{c}0 / 32 \\
0.0 \%\end{array}$ & (Ac) & $\begin{array}{l}0 / 14 \\
0.0 \%\end{array}$ & (Ad) & $\begin{array}{c}0 / 4 \\
0.0 \%\end{array}$ & (Ac) & $\begin{array}{c}0 / 25 \\
0.0 \%\end{array}$ & (Af) & $\begin{array}{c}0<20 \\
0.0 \%\end{array}$ & (Ag) & $\begin{array}{l}0 / 101 \\
0.0 \%\end{array}$ \\
\hline $\begin{array}{l}\text { “Normal” There- } \\
\text { Constructions }\end{array}$ & $(\mathrm{Na}$ & $\begin{array}{l}9 \quad / 1947 \\
0.5 \%\end{array}$ & $(\mathrm{Nb})$ & $\begin{array}{l}\mathbf{6} / 1863 \\
\mathbf{0 . 3 \%}\end{array}$ & $(\mathrm{Nc})$ & $\begin{array}{l}\mathbf{2} / 1959 \\
\mathbf{0 . 1} \%\end{array}$ & (Nd) & $\begin{array}{c}\mathbf{0} \succ 98 \\
\mathbf{0 . 0} \%\end{array}$ & $(\mathrm{Ne})$ & $\begin{array}{c}13 / 1934 \\
\mathbf{0 . 7} \%\end{array}$ & $(\mathrm{Nf})$ & $\begin{array}{l}\mathbf{8} / 1946 \\
\mathbf{0 . 4 \%}\end{array}$ & (Ng) & $\begin{array}{c}38 / 9747 \\
0.4 \%\end{array}$ \\
\hline TOTAL & & $\begin{array}{l}9 / 1953 \\
0.5 \%\end{array}$ & (Tb) & $\begin{array}{l}6 / 1895 \\
0.3 \%\end{array}$ & $(\mathrm{Tc})$ & $\begin{array}{l}\mathbf{2} \gamma^{1973} \\
\mathbf{0 . 1} \%\end{array}$ & (Td) & $\begin{array}{l}0 / 102 \\
\mathbf{0 . 0} \%\end{array}$ & $(\mathrm{Te})$ & $\begin{array}{c}13 / 1959 \\
0.7 \%\end{array}$ & $(\mathrm{Tf})$ & $\begin{array}{l}\mathbf{8} / 1966 \\
\mathbf{0 . 4 \%}\end{array}$ & (Tg) & $\begin{array}{c}38 / 9848 \\
0.4 \%\end{array}$ \\
\hline
\end{tabular}

$(\%=\#$ of negatives in each environment $\div$ \# of constructions in each environment $\times 100)$

Table 11. Breakdown of Negatives in TAs

\begin{tabular}{|c|c|c|c|c|c|c|c|c|c|c|c|c|c|c|c|}
\hline & SPOKEN \& WRITTEN & \multicolumn{2}{|c|}{ There is } & \multicolumn{2}{|c|}{ There's } & \multicolumn{2}{|c|}{ There are } & \multicolumn{2}{|c|}{ There're } & \multicolumn{2}{|c|}{ There was } & \multicolumn{2}{|c|}{ There were } & \multicolumn{2}{|c|}{ TOTAL } \\
\hline A & $-n^{\prime} t$ & (Aa) & 0 & (Ab) & 0 & (Ac) & 1 & (Ad) & 0 & (Ae) & 0 & (Af) & 0 & (Ag) & 1 \\
\hline B & not & (Ba) & 0 & (Bb) & 4 & (Bc) & 2 & (Bd) & 0 & (Be) & 0 & (Bf) & 0 & (Bg) & 6 \\
\hline $\mathrm{C}$ & never & (Ca) & 0 & (Cb) & 0 & $(\mathrm{Cc})$ & 0 & $(\mathrm{Cd})$ & 0 & $(\mathrm{Ce})$ & 0 & (Cf) & 0 & $(\mathrm{Cg})$ & 0 \\
\hline D & hardly & (Da) & 0 & (Db) & 0 & (Dc) & 0 & (Dd) & 0 & (De) & 0 & (Df) & 0 & (Dg) & $\mathbf{0}$ \\
\hline E & no longer & (Ea) & 0 & (Eb) & 0 & (Ec) & 0 & (Ed) & 0 & $(\mathrm{Ee})$ & 0 & $(\mathrm{Ef})$ & 0 & (Eg) & 0 \\
\hline $\mathrm{F}$ & neither & (Fa) & 0 & $(\mathrm{Fb})$ & 0 & $(\mathrm{Fc})$ & 0 & (Fd) & 0 & $(\mathrm{Fe})$ & 0 & $(\mathrm{Ff})$ & 0 & $(\mathrm{Fg})$ & o \\
\hline G & scarcely & (Ga) & 0 & (Gb) & 0 & (Gc) & 0 & (Gd) & 0 & $(\mathrm{Ge})$ & 0 & (Gf) & 0 & (Gg) & 0 \\
\hline $\mathrm{H}$ & seldom & (Ha) & 0 & $(\mathrm{Hb})$ & 0 & $(\mathrm{Hc})$ & 0 & (Hd) & 0 & $(\mathrm{He})$ & 0 & (Hf) & 0 & $(\mathrm{Hg})$ & 0 \\
\hline I & rarely & (Ia) & 0 & (Ib) & 0 & (Ic) & 0 & (Id) & 0 & (Ie) & 0 & (If) & 0 & (Ig) & 0 \\
\hline $\mathrm{J}$ & TOTAL & (Ja) & 0 & (Jb) & 4 & (Jc) & 3 & (Jd) & 0 & (Je) & 0 & (Jf) & 0 & $(\mathrm{Jg})$ & 7 \\
\hline
\end{tabular}

Table 12. Breakdown of Negatives in NTCs

\begin{tabular}{|c|c|c|c|c|c|c|c|c|c|c|c|c|c|c|c|}
\hline 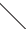 & SPOKEN \& WRITTEN & \multicolumn{2}{|c|}{ There is } & \multicolumn{2}{|c|}{ There's } & \multicolumn{2}{|c|}{ There are } & \multicolumn{2}{|c|}{ There're } & \multicolumn{2}{|c|}{ There was } & \multicolumn{2}{|c|}{ There were } & \multicolumn{2}{|c|}{ TOTAL } \\
\hline A & $-n^{\prime} t$ & (Aa) & 88 & (Ab) & 0 & (Ac) & 40 & (Ad) & 0 & (Ae) & 60 & (Af) & 58 & (Ag) & 246 \\
\hline B & not & (Ba) & 23 & (Bb) & 40 & (Bc) & 10 & (Bd) & 3 & (Be) & 14 & (Bf) & 9 & (Bg) & 99 \\
\hline $\mathrm{C}$ & never & (Ca) & 2 & (Cb) & 3 & $(\mathrm{Cc})$ & 0 & (Cd) & 0 & (Ce) & 8 & $(\mathrm{Cf})$ & 2 & $(\mathrm{Cg})$ & 15 \\
\hline D & hardly & (Da) & 0 & (Db) & 3 & (Dc) & 1 & (Dd) & 0 & (De) & 2 & (Df) & 2 & (Dg) & 8 \\
\hline E & no longer & (Ea) & 3 & $(\mathrm{~Eb})$ & 0 & $(\mathrm{Ec})$ & 1 & (Ed) & 0 & (Ee) & 1 & (Ef) & 1 & $(\mathrm{Eg})$ & 6 \\
\hline $\mathrm{F}$ & neither & (Fa) & 2 & $(\mathrm{Fb})$ & 0 & $(\mathrm{Fc})$ & 0 & (Fd) & 0 & $(\mathrm{Fe})$ & 1 & $(\mathrm{Ff})$ & 1 & $(\mathrm{Fg})$ & 4 \\
\hline G & scarcely & (Ga) & 1 & (Gb) & 0 & (Gc) & 0 & (Gd) & 0 & (Ge) & 1 & (Gf) & 0 & $(\mathrm{Gg})$ & 2 \\
\hline $\mathrm{H}$ & seldom & (Ha) & 1 & $(\mathrm{Hb})$ & 0 & (Hc) & 0 & (Hd) & 0 & (He) & 0 & (Hf) & 1 & $(\mathrm{Hg})$ & 2 \\
\hline I & rarely & (la) & 0 & (Ib) & 0 & (Ic) & 0 & (Id) & 0 & (Ie) & 0 & (If) & 1 & (Ig) & 1 \\
\hline $\mathrm{J}$ & TOTAL & (Ja) & 120 & $(\mathrm{Jb})$ & 46 & (Jc) & 52 & (Jd) & 3 & (Je) & 87 & (Jf) & 75 & $(\mathrm{Jg})$ & 383 \\
\hline
\end{tabular}

show breakdowns of the negatives in each construction. ${ }^{20}$ In NTCs, there occur various kinds of "informationally rich" negatives (from $\mathrm{C}$ through I in Table 12), whereas in TAs, negatives of this kind never occur. Thus, it can

${ }^{20}$ Here, I give some examples of NTCs containing "informationally rich" negatives just for reference, instead of TAs, as there are no such examples of TAs:

(i) No, there was hardly anybody at our English seminar this morning, ...

(ii) There were no longer groups of pupils in any one class ... 
be posited that TAs generally do not (or at least hardly) take "informationally rich" negatives.

The other phenomenon that I would like to point out concerns the contraction phenomenon of negatives with be-verbs as in (19):

(19) a. There aren't many people say that nowadays. $\quad(=(18 \mathrm{c}))$

b. You know, there isn't a thin line between love and infatuation.

$[\mathrm{NTC}]$

c. No there wasn't anyone after me.

[NTC]

Table 13 shows the frequency of this phenomenon in TAs and NTCs. Note that there are less contracted negatives in TAs (14.3\%) than in NTCS (71.3\%).

Table 13. The Frequency of Contracted Negative Forms in Each Construction (TAs vs. NTCs)

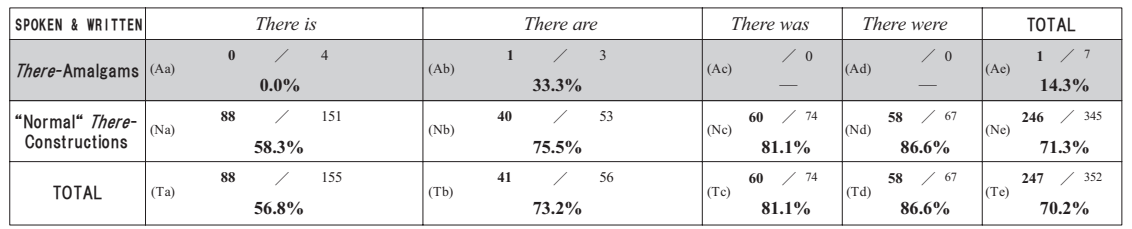

$(\%=\#$ of contracted negative forms in each environment $\div \#$ of sentences negated by not in each environment $\times 100$ )

The contrastive distributions of negatives presented in this subsection may also suggest the special status of there be. In the following section, we will discuss implications of the peculiarities of TAs detected above.

\section{One Feasible Story: There $B e$ as a Particle}

Having surveyed the idiosyncrasies of TAs, I will now begin to analyze their implications. What I claim here first is that the peculiarities of logical subjects in TAs detected in Sections 4.2.1 and 4.2.2 mirror the fact that $a$ be-verb (or there be as a chunk) in TAs has weaker ties with the following noun (i.e. a logical subject) than a be-verb in NTCs does. In this case, the status of a noun as a (logical) subject in the "first clause" (i.e. there be) is to some degree lowered or completely lost, which at the same time elevates the noun's status as a subject in the "second clause." Figures 1, 2 and 3 help to capture this image.

Although the results concerning logical subjects in TAs have led me to 


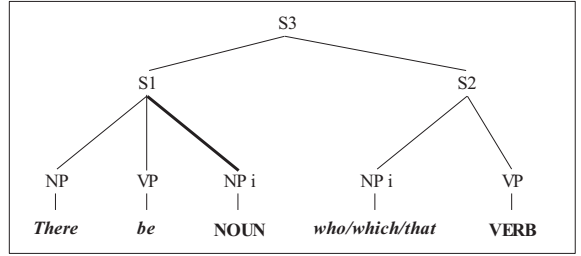

Figure 1. The "Normal" Type

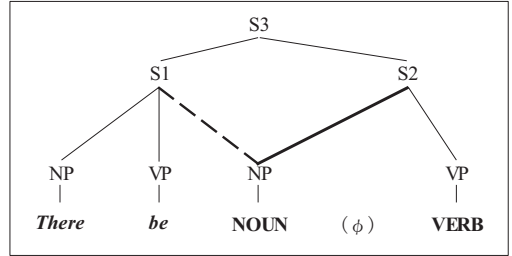

Figure 2. The "Apo Koinou” Type

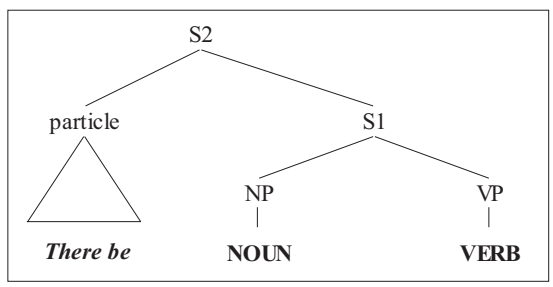

Figure 3. The "Particle" Type

(Takaki $(2009: 8,45,50))$

only claim weaker ties between a $b e$-verb and the following noun (i.e. logical subject) in TAs, the other findings concerning negatives enable me to go further. Here, based on the fact that a be-verb in TAs never occurs with an "informationally rich" negative and there are less contracted negative forms in TAs, I venture to argue that a be-verb in TAs more or less has lost its "verbhood" (or there be as a chunk has lost some of its "clausehood"). That is, there be as a chunk has become an "independent phrase" (not "dependent clause") (Figure 3). This is also supported by the results of the questionnaire on tag questions provided in Takaki (2010b):

(20) a. There is some men go to church, $\{*$ isn't there/don't they\}?

b. There's he is angry, $\left\{*^{\prime}\right.$ isn't there/isn't he $\}$ ?

The fact that the tag question in each sentence agrees with the subject and the verb in the "second clause," suggests that the be-verb in each sentence has lost some of its verbness and there be as a chunk has become just some kind of independent phrase or adverb. ${ }^{21}$

21 Of course, I am not saying that the results of the questionnaire are sufficient to confidently argue that there be in TAs is an independent phrase or an adverb. However, these data at least suggests that the chunk there be in TAs is no longer a main clause but a subordinate clause both at the conceptual and linguistic levels, which merits grave consideration. 
Here, like Harris and Vincent (1980) and Yasui (1987), I also term this independent phrase a particle. I use the term "particle," as Yasui seems to do, in the sense of "items that do not fit easily into syntactic and semantic generalizations about the language," or "words left over when all the others have been assigned to syntactic categories" (Zwicky (1985: 290, 292)). By this definition, "with/without inflection" is not a criterion for judging whether items are a particle. ${ }^{22}$

I must here add and emphasize this: My claim differs from Harris and Vincent, in that I hypothesize, from the descriptions in Section 4, that there is still more or less possibility that every sequence (i.e. there be), not there's only, is an item of this kind. ${ }^{23,24}$

To my knowledge, there are no previous studies of TAs which address the morphological and syntactic behavior of TAs as elaborately as the present article. The descriptions of TAs with these viewpoints have definitely reinforced the hypothesis of the independent status of there be in TAs. At this point, I can now with more confidence postulate the existence of TAs of the particle-type. However, of course, I do not mean that all TAs should be grouped into this particle-type. I accept the "Apo Koinou" Hypothesis as well. This idea of "apo koinou-and-particle" follows from the fact that some TAs properly observe such rules as number concord and indefinites for a subject as in (21):

22 Specifically, by the term particle, I am referring to two kinds of adverbials: There be which works as a "pure" adverb, and there be which works both as a noun + a verb syntactically and as an adverb semantically. As for the second type, it could be said that there be is both an argument of the sentence and a non-argument at the same time. This type of construction is very similar to the Chance-Construction as in (ii):

(i) Chances are, he goes to church, doesn't he?

(ii) The chances are that he goes to church, doesn't he?

Chances are in (i) can be said a "pure" adverb (cf. probably and perhaps), whereas The chances are (that) in (ii) could be a noun + a verb syntactically, and an adverb semantically. Because of this kind of peculiarity, and lack of any other suitable labels, I have chosen to use the term "particle" for there be in TAs (cf. There is no doubt that he goes to church).

${ }^{23}$ Nevertheless, it is true, judging from the findings, that there's is the most particlelike item, as is often argued in the literature (Breivik and Martínez-Insua (2008), Yaguchi (2007, 2008)).

24 We may leave semantic and functional discussions of TAs to Takaki (2009: Ch. 5, 2010a), because to argue these points would take us beyond the scope of this paper, which is just to suggest the possibility of there be as a particle. 
(21) a. ... there's a nurse goes in to bath her every day ...

b. There aren't many people say that nowadays.

c. ... there were other men did this sort of thing.

In addition, there is still a reasonable possibility of the "undistinguishable" pronouns ((Ua) in Table 8) being used as the accusative. In this sense, some TAs are, as intuition suggests, judged as an apo koinou, since there are no encouraging and persuasive reasons to classify them as a particle, then we regard them as cases of apo koinou. Here, with all things considered, There-Amalgams can be assumed to be an amalgam-particle continuит.

\section{Concluding Remarks}

The "Particle" Hypothesis was a weak and minor one before the advent of this paper. However, now that, by using the data collected from the BNC in a novel manner, I have shown that There-Amalgams of the particletype also exist, the hypothesis is no longer just a myth. We now have two types of TAs on our hands, and we have to take the next step forward to semantic, functional and pragmatic analyses of these constructions. At present, we have very little exhaustive research on TAs in such aspects. ${ }^{25}$ It is hoped that the outcome of this present study can serve as a "springboard" for more elaborate research into TAs in the future.

\section{REFERENCES}

Ando, Sadao (2005) Gendai Eibunpo Kogi (Lectures on Modern English Grammar), Kaitakusha, Tokyo.

Ando, Sadao (2008) Eigo no Bunkei: Bunkei ga Wakareba Eigo ga Wakaru (Sentence Patterns in English: To Understand Sentence Patterns Is to Understand English), Kaitakusha, Tokyo.

Breivik, Leiv Egil and Ana E. Martínez-Insua (2008) "Grammaticalization, Subjectification and Non-Concord in English Existential Sentences," English Studies 89, 351-362.

Crawford, William J. (2005) "Verb Agreement and Disagreement: A Corpus Investigation of Concord Variation in Existential There + Be Constructions," Journal of English Linguistics 33, 35-61.

25 For semantic and functional discussions of TAs, refer to Takaki (2009: Ch. 5, 2010a), and for an account of cognitive mechanisms underlying TAs, see Takaki (2010b). 
Curme, George O. (1931) Syntax (A Grammar of the English Language, Vol. 3), D. C. Health, Boston/London.

Harris, Martin and Nigel Vincent (1980) “On Zero Relatives,” Linguistic Inquiry 11, 805-807.

Hayase, Naoko and Yuko Horita (2005) Ninchibunpo no Shintenkai: Kategorika to Yohokibanmoderu (Cognitive Grammar: Categorization and a Usage-based Model), Kenkyusha, Tokyo.

Hopper, Paul J. (1998) "Emergent Grammar," The New Psychology of Language: Cognitive and Functional Approaches to Language Structure, ed. by Michael Tomasello, 155-175, Lawrence Erlbaum Associates, Mahwah, NJ.

Huddleston, Rodney and Geoffrey K. Pullum (2002) The Cambridge Grammar of the English Language, Cambridge University Press, Cambridge.

Ishibashi, Kotaro et al. (1973) Gendai Eigogaku Jiten (Seibido's Dictionary of English Linguistics), Seibido, Tokyo.

Jespersen, Otto (1927, rpt. 1949) A Modern English Grammar on Historical Principles, Part III: Syntax, Vol. 2, George Allen \& Unwin, London.

Kuno, Susumu and Ken-ichi Takami (2004) Nazotoki no Eibunpo: Kanshi to Meishi (Riddles of English Grammar: Articles and Nouns), Kurosio, Tokyo.

Lakoff, George (1974) "Syntactic Amalgams," CLS 10, 321-344.

Lambrecht, Knud (1988) "There Was a Farmer Had a Dog: Syntactic Amalgams Revisited," BLS 14, 319-339.

Langacker, Ronald W. (2002) Concept, Image, and Symbol: The Cognitive Basis of Grammar, 2nd ed., Mouton de Gruyter, Berlin.

Nakazawa, Noriko (2006) "Theresesshokusetsu to Kankeidaimeishi no Kenzaika: Nasariraimu no Baai (The There Contact Clause and Emergence of the Relative Pronoun : In the Case of Nursery Rhymes)," Studies of Modern English 22, 71-91.

Prince, Ellen F. (1981) "Toward a Taxonomy of Given-New Information," Radical Pragmatics, ed. by Cole Peter, 223-255, Academic Press, New York.

Quirk, Randolph, Sidney Greenbaum, Geoffrey Leech and Jan Svartvic (1985) A Comprehensive Grammar of the English Language, Longman, London.

Rando, Emily and Donna J. Napoli (1978) "Definites in There-Sentences," Language 54, 300-313.

Saito, Toshio, Junsaku Nakamura and Ichiro Akano, eds. (1998) Eigo Kopasu Gengogaku (English Corpus Linguistics), Kenkyusha, Tokyo.

Takaki, Isamu (2008) “\#?There Is No Longer 'There Contact Clauses' Are Regarded as 'Amalgamated,"' paper presented at the 1st International Spring Forum of the English Linguistic Society of Japan.

Takaki, Isamu (2009) "A Cognitive Approach to the Anacoluthia Phenomenon in English: Semantic and Pragmatic Motivations for There-Amalgams," MA thesis, Kyoto University.

Takaki, Isamu (2010a) "Subtypes of There-Amalgams: Their Meanings/Functions," JELS 27, 267-276.

Takaki, Isamu (2010b) “Thereamarugamukobun o Umidasu Ninchimekanizumu (Cog- 
nitive Mechanisms Underlying the There-Amalgam Construction)," Proceedings of the 10th Annual Meeting of the Japanese Cognitive Linguistics Associationon 10 .

Tanaka, Harumi et al. (1988) Gendai Gengogaku Jiten (Seibido's Dictionary of Linguistics), Seibido, Tokyo.

Watanuki, Yo, Yukihisa Miyakawa, Taketoshi Sugai, Naohiro Takamatsu and Mark Petersen (2000) Roiyaru Eibunpo (Royal English Grammar with Complete Examples of Usage), Obunsha, Tokyo.

Yaguchi, Michiko (2007) "There $+B e+\mathrm{S}+\mathrm{V}$ Kobun no Rekishiteki Suii ni Tsuite (On Historical Transition of the There $+B e+\mathrm{S}+\mathrm{V}$-Construction)," paper presented at the workshop of the Japanese Association for Studies in the History of the English Language held at Kyoto University on October 13, 2007.

Yaguchi, Michiko (2008) "Gendaieigo ni okeru there+be no Bunpoka (Grammaticalization of There+Be in Present-Day English)," paper presented at the 32nd Conference of the JAECS (Japan Association for English Corpus Studies) held at Tokyo University of Foreign Studies on October 4, 2008.

Yasui, Minoru (1987) Reikai Gendai Eibunpo Jiten (The Encyclopedia of Contemporary English Grammar), Taishukan, Tokyo.

Zwicky, Arnold M. (1985) "Clitics and Particles," Language 61, 283-305.

\section{Corpus}

The British National Corpus (BNC)

[received September 20 2009, revised and accepted January 18 2010]

Department of Human Coexistence

Graduate School of Human and Environmental Studies

Kyoto University

Yoshida-Nihonmatsu-cho Sakyo-ku, Kyoto-shi

Kyoto $606-8501$

e-mail: rebornn2005@yahoo.co.jp 